\title{
A DIMENSÃO ESPACIAL NO "AMÉNAGEMENT" DO TERRITÓRIO - O EXEMPLO FRANCÊS ${ }^{1}$
}

\section{La dimension spatiale dans l'aménagement du territoire - l' exemple français}

\author{
André FICHER *
}

\begin{abstract}
RESUMO
O que significa a dimensão espacial para o "aménagement"? As políticas de "aménagement" devem sempre ter em conta: as contingências impostas pelos espaços de intervenção, as divergências que opõem o espaço institucional e o espaço das empresas, a acentuação das clivagens qualitativas no espaço geográfico. Outros fenômenos concorrem para a "complexização" desta dimensão, tais como: a diversidade das estratégias espaciais dos atores, as tentativas de reajustamentos territoriais, a procura por novas tecnologias da informação e da comunicação.
\end{abstract}

\section{Palavras-chave:}

"Aménagement", territórios, estratégias espaciais, reajustamentos, segregações.

\section{RÉSUMÉ}

Que signifie la dimension spatiale au regard de l'aménagement?

Les politiques d'aménagement doivent tout à la fois prendre en compte: les contraintes imposées par les espaces d'intervention, les divergences qui opposent l'espace institutionnel et l'espace des entreprises, l'accentuation des clivages qualitatifs dans l'espace géographique.

D'autres phénomènes concourent à la compléxification de cette dimension, tels que: la diversité des stratégies spatiales des acteurs, les tentatives de réajustements territoriaux, le recours aux nouvelles technologies de l'information et de la communication.

\section{Mots clés:}

Aménagement, territoires, stratégies spatiales, réajustements, ségrégations.
- Tradução: Nathalie DESSARTRE-MENDONÇA.
Professor Emérito Universidade de Paris I. 


\section{PRÓLOGO}

A- As obras e os artigos que tratam do "aménagement" ${ }^{2}$ do território, mesmo adotando uma abordagem baseada nos tipos de meios ("aménagement" urbano...) - nos setores de atividade ("aménagement" industrial...) - no espaço global (o "aménagement" na França...) ou ainda nas políticas e nos dispositivos institucionais aplicados (a descentralização...), têm em comum, desde os anos sessenta, o fato de privilegiar amplamente os dados factuais. Em outras palavras, a apreciação dos resultados adquiridos é mais valorizada que a reflexão fundamental sobre a eficiência das intervenções nos territórios.

Poucos são os estudos que dedicam espaço importante à reflexão sobre o "porquê" e o "como" das "questões que se apresentam" (as problemáticas do "aménagement"), assim como sobre as opções de modalidade de intervenção e suas implicações (os processos do "aménagement").

O presente artigo se propõe a desenvolver tal reflexão de fundo sobre a dimensão espacial no "aménagement", dimensão por demais vezes reduzida à única idéia de escala geográfica dos territórios estudados. Nesta reflexão talvez encontremos alguns elementos de resposta para uma pergunta tão antiga quanto aquela direcionada às políticas de intervenção sobre os territórios: existe uma ou várias "escalas pertinentes" para o "aménagement" do território?

É claro que esta reflexão postula a especificidade do "aménagement" do território ou, mais exatamente, aquela da ação dos "aménageurs"3 (em relação à ação dos eleitos, dos políticos, dos economistas). Esta especificidade ultrapassa os limites da simples preocupação em otimizar os efeitos espaciais das intervenções considerando a dupla coerência espacial e temporal das estratégias escolhidas; trata-se ao mesmo tempo de uma questão de problemática e de métodos de intervenção.

A esta altura da reflexão, uma dupla observação liminar se impõe: de um lado, a dimensão espacial não poderia ter o mesmo significado em período de crescimento geral e em período de crise generalizada (o que apresenta o problema das relações funcionais entre os espaços centrais e os espaços periféricos); por outro lado, assim como o tempo, o espaço do crescimento econômico não é aquele do desenvolvimento social (de onde surge diretamente a questão da perti-nência dos recortes territoriais).

B - Assim como muitas outras disciplinas das ciências humanas e sociais, a geografia contemporânea sofreu muito com as imprecisões que caracterizam grande parte dos seus conceitos e da sua terminologia usual, o que explica uma "eficiência deficitária" agravada pelas ambigüidades associadas à emergência da moda semântica (por ex: o termo: território). Para que nossa reflexão teórica seja compreensiva, três dos principais conceitos evocados devem ser, de antemão, claramente definidos: os conceitos de "aménagement" do território, de território, de planejamento.

Propomos definir o "aménagement" como: "o conjunto das intervenções do poder público baseadas em objetivos públicos e em projetos sociais coletivos e que visam, pela aplicação de políticas de monitoramento (resposta a uma demanda expressa) e de políticas de treinamento (antecipação de uma solicitação futura), a requalificar espaços degradados ou em crise, a aumentar a atratividade e os potenciais de certos territórios, a garantir um mínimo de equilíbrio inter-regional dentro do espaço nacional". Evidentemente, tal definição levanta muitas questões, e particularmente estas: como evitar as incoerências entre as políticas de "aménagement" do poder público e as diversas políticas econômicas e sociais do Estado - como conciliar a ação territorial dos poderes públicos e as estratégias desenvolvidas pelas empresas privadas?

Em relação às preocupações do "aménagement", o conceito de território poder ser definido da maneira seguinte: "um espaço delimitado e apropriado, no qual se exercem poderes (controle, organização), se inscrevem projetos sociais coletivos (planejamento, desenvolvimento, "aménagement"), se expressam estratégias de valorização (exploração dos recursos), se afrontam os interesses mais ou menos conflituosos dos diferentes atores". Com este tipo de território, que é sobretudo um território-projeto e não um simples território-objeto, estamos longe do espaço neutro e indiferente da teoria econômica neoclássica. Este território é um espaço sociopolítico associado a projetos, que oferece potenciais e oportunidades, no qual os vínculos horizontais de proximidade tendem a substituir gradativamente as tradicionais relações hierárquicas verticais. À diferença do espaço-contenant ${ }^{4}$ de outrora, o de hoje pode ser muito sensível aos efeitos de uma ou várias racionalidades.

\footnotetext{
2 Em português, não existe tradução exata do conceito. Ele é muitas vezes utilizado no sentido de "planejamento", "organização" ou de "ordenamento do território". O "aménagement" implica numa dimensão política do território.

3 Pode ser entendido como "planejadores".

${ }^{4}$ Literalmente significa "espaço que contém", "espaço que abarca" ou "espaço recipiente".
} 
Seja ele econômico, social, territorial, global, o planejamento, presente em programas e projetos, consiste sempre em organizar o crescimento e o desenvolvimento para o futuro, em controlar as evoluções setoriais e espaciais em vez de deixar que se desenvolvam evoluções espontâneas suscetíveis de gerar muitos riscos e incoerências. Qualquer planejamento supõe uma definição de objetivos, de um orçamento, de um cronograma e de um território. Como a sociedade não pode atender a todas as necessidades ao mesmo tempo, todo planejamento implica também escolher prioridades (entre as ações futuras) e arbitragens (para os investimentos públicos entre os diversos interesses em concorrência), assim como recorrer a diversas técnicas de antecipação (projeções, previsões, prospectiva). Fica evidente que o planejamento postula um alto nível de consenso entre os "décideurs", ${ }^{5}$ o que implica no mínimo duas perguntas: quais são as relações entre o "aménagement" tecnocrático (as decisões tomadas de cima) e o "aménagement" democrático (as decisões tomadas mais próximas da população envolvida)? E as pequenas coletividades locais têm os meios (humanos, financeiros e técnicos) de responder às exigências do planejamento?

O que se pode concluir deste prólogo? Reter-se-ão aqui as proposições seguintes: "aménager" é antes de tudo escolher, fazer escolhas que se expressam em políticas de intervenções - 0 "aménagement" só pode ser global (ao mesmo tempo setorial e espacial) e não pode ser limitado nem à ação em um domínio particular (a cidade, a indústria, os transportes), nem à utilização de uma caixa de ferramentas (instrumentos legislativos, jurídicos, econômicos) - Não se pode realizar um "aménagement" sem saber com precisão "quem faz o que e quem decide o quê" (neste caso, a repartição territorial dos poderes e das competências é capital para entender a diversidade das estratégias de "aménagement").

\section{O ESPAÇO EM QUESTÃO}

A - Todas as considerações que podem ser desenvolvidas a respeito dos espaços e dos territórios são profundamente marcadas pela influência de um fator que dá complexidade à dimensão espacial: a diversidade dos atores que intervêm no "aménagement" (população, eleitos, administrações, coletividades, empresas, Estado). Esta diversidade é antes de tudo a dos interesses que se expressam no espaço, de onde uma inevitá- vel multiplicação das divergências, das contradições e dos riscos de conflitos.

A passagem do sistema de produção fordista ao sistema de produção flexível, assim como a passagem do modelo do Estado-providência ao modelo de desenvolvimento endógeno por baixo, multiplicaram ainda mais estes antagonismos potenciais, reforçando a competição pelo espaço. Hoje, a concorrência espacial se expressa em todos os níveis escalares, pois cada coletividade se esforça para atrair um máximo de atividades e para ser a mais interessante (portanto a mais competitiva) possível.

Levando em consideração esta diversidade dos atores, talvez seja realista considerar que a dimensão espacial concreta do "aménagement" é aquela na qual se inscreve "o impossível compromisso optimum" procurado pelas políticas de "aménagement".

B - É curioso constatar que uma pergunta fundamental está praticamente ausente dos trabalhos dos geógrafos relacionados ao "aménagement": sobre qual espaço se quer atuar? A pergunta deve ser feita pelo fato de que o espaço geográfico é simultaneamente o objeto de uma dupla estruturação, com características e com implicações muitos distintas: uma estruturação espacial segundo os recortes institucionais, de um lado, e a estruturação espacial pela organização funcional das empresas, de outro.

Os recortes institucionais, projeção das estruturas político-administrativas sobre o território, traduzemse por uma hierarquia espacial de unidades territoriais justapostas e imbricadas, desde o território nacional do Estado - até o território municipal - coletividades locais. Cada unidade territorial corresponde então a um domínio de competência dos eleitos e da administração, um domínio com limites espaciais muito precisos, um domínio no qual se acumulam estoques (população, recursos, atividades...) destinados a evitar o declínio, até mesmo a desertificação. Dada a função mais importante desempenhada por estes espaços institucionais para com as políticas públicas de "aménagement", sua característica principal (sobretudo na França) é o peso e a permanência de sua inércia espacial: dentro dos seus limites, estas unidades evoluem muito devagar, ao ritmo das escassas reformas administrativas, enquanto nos seus conteúdos socioeconômicos sofrem os efeitos, muitas vezes brutais, das crises econômicas setoriais.

Bem diferente é o espaço das empresas, estruturado, no modelo informativo, por um conjunto de

\footnotetext{
${ }^{5} \mathrm{Na}$ política e/ou na administração se refere à pessoa física ou moral que tem o poder de decisão (em matéria de meio ambiente, de "aménagement" do território - banqueiros, empreendedores).
} 
pontos (localização dos estabelecimentos, dos serviços externos, dos fornecedores e dos clientes) entre os quais se tecem redes complexas de fluxo (informações, homens, produtos). Trata-se aqui de um espaço concorrencial que deve, senão oferecer "localizações ótimas", pelo menos permitir à empresa melhorar a sua competi-tividade garantindo uma melhor rentabilidade de suas implantações (a dimensão espacial, como a dimensão temporal, torna-se cada vez mais uma dimensão estratégica para a empresa, o que mostra claramente a prática das deslocalizações). E este espaço, por definição desigual, caracteriza-se sobremaneira por sua grande mobilidade espacial potencial, localizações e fluxos podendo evoluir muito rápido, ao ritmo das crises econômicas e das conjunturas políticas e tecnológicas.

O espaço geográfico vai evoluir segundo o modelo do espaço (desigual) das empresas (o que sugere a aceitação de políticas territoriais muito seletivas) ou então segundo os princípios que definem o espaço (igualitário) dos poderes públicos (justificando a prática da pulverização territorial de investimentos)?

C - As políticas de "aménagement" devem responder às necessidades das populações; não se pode então "abrir mão" de partes do território. As mesmas políticas de "aménagement" devem satisfazer às exigências de rentabilidade e de competitividade das empresas; não se pode então "negligenciar" as novas tecnologias nem os espaços dinâmicos. Este é só um exemplo de dilema com o qual é confrontada a política de "aménagement" do Estado. A oposição entre os dois tipos de espaço dá origem a muitos outros dilemas, graças às diferenças em: capacidades de resposta às exigências de flexibilidade associadas ao novo modo de produção, as relações entre as lógicas exógenas e endógenas de desenvolvimento local, os ritmos das regulações econômicas e sociais, as capacidades em antecipar e em criar meios socioeconômicos atrativos... etc.

Nas escalas infra-regionais, o espaço institucional sofre muitas vezes de obsolescência. Regiões, departamentos e municípios só conheceram, desde os anos cinqüenta, ínfimas modificações do seu território e dos seus limites, enquanto os seus conteúdos socioeconômicos foram mais ou menos transformados pelos efeitos: A/ na França: do êxodo rural e da urbanização acelerada, das políticas de descentralização e de transferência das competências, das crises das antigas bacias industriais, do aumento da diferença entre as regiões, centros e os espaços periféricos. B/ no plano global: da passagem do crescimento à crise, do declínio do Estado-providência e do impulso do desenvolvimento por baixo, da mudança de sistema produtivo, da inovação tecnológica e da terceirização das atividades produti- vas, da emergência da dimensão européia e da globalização dos intercâmbios. Dada a amplitude destes intercâmbios, fica claro que os quadros rígidos propostos pelos espaços institucionais são cada vez menos adaptados às exigências dos planejamentos atuais e ao longo prazo. Os espaços de intervenção devem permanecer imutáveis ou devem ser modulados segundo as necessidades do "aménagement"? Esta é toda a problemática do reajuste territorial.

D - Na evolução dos seus conteúdos socioeconômicos e de sua organização interna, o espaço francês e seus territórios, assim como a Europa como um todo, sofrem diretamente os efeitos daquilo que poderíamos chamar de "tendências geográficas de peso". O importante é constatar que estas tendências conduzem a um mesmo resultado dentro do espaço geográfico: a acentuação das segregações qualitativas entre os territórios dinâmicos e as regiões periféricas.

A primeira destas "tendências geográficas de peso" é aquela da metropolização. Lugar de concentração dos poderes de alto nível, das funções mais diversificadas e sofisticadas, das populações ativas mais qualificadas, das infra-estruturas de relações mais eficientes, a metrópole (definida pela trilogia poderes-funções-capacidade de polarização) oferece o meio socioeconômico mais flexível, o mais apto a gerar inovações, o mais atrativo para as atividades de alto nível. Entretanto, a metrópole não é um meio atrativo para todos: os custos de implantação gerados por ela são tamanhos que ela se torna progressivamente acessível somente às atividades que geram um forte valor agregado e às populações que dispõem de rendas elevadas. A metrópole desempenha portanto um duplo papel perante espaços geográficos: um papel de "bomba de aspiração" atraindo as atividades sofisticadas, um papel de "bomba de rejeição" expulsando para fora as atividades mais banais e os ativos com nível de renda mais baixo. Não é portanto excessivo dizer que como processo dinâmico a metrópole é parcialmente responsável por um certo enfraquecimento da vitalidade das cidades de menor importância, assim como da tendência à "dispersão do banal" para espaços periféricos (mas qual é então a verdadeira eficiência das políticas de descentralização?).

Para o seu transporte, os usuários e ainda mais as empresas são sensíveis às vantagens fornecidas pela dupla freqüência/velocidade. Não surpreende portanto constatar que a segunda das "tendências geográficas de peso" corresponda ao desenvolvimento das infraestruturas e das redes de transporte de grande velocidade. Entretanto, estes desenvolvimentos geram, por sua vez, segregação no espaço geográfico: provocando a concentração progressiva da circulação nos gran- 
des eixos - levando à criação de "pontos fortes do espaço" lá onde existem possibilidades de acesso direto aos grandes eixos. Estes "pontos fortes", ao oferecerem uma acessibilidade máxima, são muito atrativos para as empresas que podem beneficiar-se nestes lugares de uma verdadeira renda de localização, portanto de uma vantagem garantida de competitividade. Pelo contrário, todas as atividades localizadas fora destes lugares privilegiados são penalizadas pela concorrência. Evidentemente, estes pontos são lugares de concentração das atividades de alto nível, enquanto as atividades e as populações que não podem pretender a isso são rejeitadas para os espaços menos atrativos (e menos competitivos) das periferias locais, regionais, nacionais (que muitas vezes oferecem às empresas vantagens sobre o valor dos terrenos e sobre os custos do trabalho). Por razões de competição econômica internacional, está claro que os poderes públicos não podem deixar de participar da consolidação destes pontos fortes do espaço. Mas o que advém então do princípio de equilíbrio territorial?

Terceira "tendência geográfica de peso" atual e terceiro produtor de clivagens qualitativos no espaço geográfico: o desenvolvimento tecnológico e das novas tecnologias. Concernente aos procedimentos de fabricação ou aos produtos fabricados, a inovação só pode se desenvolver em meios que oferecem, ao mesmo tempo, uma ampla oferta de externalidades de serviços uma reserva de mão de obra altamente qualificada (o famoso "viveiro") - possibilidades de tirar o melhor proveito dos efeitos cumulativos da concentração de knowhow e das capacidades de aprendizagem - das relações estreitas com os organismos privados e públicos de pesquisa... Estes meios inovadores, onde se concentram as atividades nobres, correspondem por excelência às metrópoles e tecnópoles das regiões - centros -, enquanto nas regiões periféricas se implantam sobretudo atividades banais que necessitam de tecnologias estandardizadas e uma mão de obra numerosa, porém pouco qualificada. O indispensável apoio público à inovação tecnológica só pode acentuar os desequilíbrios qualitativos no espaço, beneficiando os pontos fortes dos territórios.

Finalmente, os efeitos cumulados das "tendências geográficas de peso" levam a acentuar a natureza qualitativamente dual do espaço geográfico, no qual se opõem cada vez mais os meios dinâmicos e as regiões dependentes. Discordando certamente dos objetivos do "aménagement" social do território, esta realidade es- pacial está, sem dúvida alguma, em conformidade com os princípios da economia liberal e a tirania dos mercados.

\section{A RESPEITO DO ESPAÇO DE INTERVENÇÃO}

A - Programas, planos e esquemas se concretizam no espaço de intervenção. No que diz respeito às ações de "aménagement", este é dotado de características particulares: trata-se sempre de um espaço histórico no qual as heranças do passado podem constituir tanto obstáculos ou contingências quanto os esforços de remodelagem (o meio físico, o construído) - também é um espaço jurídico no qual as legislações e os regulamentos técnicos multiplicam as contingências e as restrições em matéria de intervenções sobre os territórios (ex: o código de urbanismo) - é o espaço da implantação dos homens e das atividades, portanto é mais ou menos acessível, mais ou menos rugoso ou fluido; é um espaço suscetível de oferecer recursos e oportunidades e cujo "valor relativo" e atratividade se modificam com as intervenções de "aménagement"; é um espaço necessariamente inscrito em uma dupla hierarquia, de meios e de competências, assim como em uma dupla gestão, administrativa e econômica; é, por fim e em todas as escalas, um espaço que constitui uma disputa entre os interesses mais ou menos contraditórios dos diversos atores envolvidos. O significado desta insípida listing 6 é claro: as ações de "aménagement" sempre são difíceis de ser definidas e ainda mas de ser aplicadas.

Na França, em particular, uma dificuldade suplementar complica ainda mais as coisas: o espaço de intervenção corresponde por demais vezes a um perímetro cuja extensão e limites não foram delimitados pelos "aménageurs" encarregados da elaboração dos programas, mas impostos pelos agentes políticos, cujos objetivos diferem muito das coerências procuradas pelos "aménageurs". Eis aqui uma das maiores fontes das dificuldades encontradas na aplicação das ações de "aménagement", mas também a origem de muitas discordâncias nos resultados conseguidos.

B - Em matéria de espaços de intervenção, a França oferece um mapa particularmente complexo. Encontram-se naquele país, com efeito: cinco níveis hierárquicos de administração territorial (dos quais os principais são as 22 regiões, os 95 departamentos e os 36.765 municípios!), numerosos espaços específicos (os

\footnotetext{
${ }^{6}$ Em inglês no texto original
} 
perímetros das cidades novas, dos parques naturais, das missões interministeriais, da montanha, do litoral, das grandes obras), várias "novas fórmulas territoriais" que visam a adaptar melhor o espaço às novas condições (as comunidades de municípios e as comunidades de cidades de 1992, os "pays" de 1995, as comunidades de aglomeração de 1999), com transferências para todas estas entidades, ainda hesitantes e parciais dos poderes e das competências do Estado para as coletividades institucionais territoriais. Mas estas transferências geralmente não são acompanhadas das transferências correspondentes dos meios financeiros necessários, o que limita consideravelmente o alcance dos projetos elaborados pelas coletividades.

A insuficiência crônica dos meios das coletividades é uma constante do sistema francês. Dos 36.765 municípios franceses, 29,3\% tinham menos de 200 habitantes em 1993 e 68,7\% tinham menos de 700 habitantes no mesmo ano. Quais podem ser então suas capacidades para gerenciar o seu território (sabendo, por outra parte, que as coletividades locais francesas têm um fraco domínio fundiário do seu território), para elaborar projetos coletivos, para antecipar o futuro? E esta fraqueza não diz respeito somente aos meios, mas também aos potenciais: das 22 regiões, uma só chega a 10.000.000 de habitantes, três somam entre 3,5 e 5,5 milhões, nove regiões têm uma população entre 1 e 2 milhões, a menor não chega a 250.000 habitantes. As regiões francesas têm a capacidade de concorrer com as regiões fortes da União Européia?

C - A incapacidade do espaço da intervenção institucional em oferecer estruturas adaptadas às necessidades do "aménagement" decorre também das estratégias espaciais utilizadas pelos distintos atores.

Dada a acuidade da concorrência espacial, o problema atual das coletividades locais é um verdadeiro problema de sobrevivência. A resposta das coletividades é quase sempre a mesma: precisa atrair atividades para poder dispor de empregos e de recursos financeiros, os dois pilares essenciais do crescimento e do desenvolvimento... Onde for, na França, vêem-se brotar as "estratégias de atração" baseadas em vantagens e facilidades múltiplas concedidas às empresas para que aceitem implantar-se: vantagens fiscais, auxílios financeiros, imobiliários e fundiários, melhoria dos transportes, criação de, externalidades de serviços (a ubiqüidade das externalidades genéricas é, neste caso, uma vantagem considerável), etc. As coletividades locais procuram portanto a solução na criação de meios e de ambientes atrativos. Só se pode constatar que, na ausência de meios e de potenciais, a maior parte das coletividades fica fora desta competição.

Para as grandes empresas, o paradigma de referência, no que diz respeito à estratégia espacial, é aquele da "rentabilidade do espaço": a escolha pelo local de implantação depende das capacidades do meio em satisfazer as exigências de funcionamento da empresa, permitindo-Ihe ao mesmo tempo minimizar os seus custos de localização e de produção e otimizar seus benefícios (de toda natureza). Estas estratégias espaciais acabam inevitavelmente sendo muito seletivas e, geralmente, benéficas para os pontos fortes dos territórios.

Nos discursos políticos e nas petições de princípio, as intervenções territoriais do Estado têm como maior objetivo lutar contra as desigualdades espaciais e os desequilíbrios inter-regionais. Na prática, o Estado não pôde evitar o rápido declínio das indústrias tradicionais, tais como as do carvão, da siderurgia e do têxtil (o que explica uma multiplicação das antigas regiões industriais em crise), mas soube desenvolver, a partir dos anos setenta, uma notável estratégia espacial de difusão da inovação tecnológica no conjunto do território nacional (não se deve deixar nenhuma região excluída) e no conjunto da estrutura econômica (todas as peque-nas empresas devem poder ser beneficiadas). A multiplicação dos organismos regionais de difusão da inovação, assim como a instalação das redes técnicas de transferência da informação, decorre desta estratégia. O que significa, sobretudo se se acrescentam os esforços desenvolvidos na questão das infraes-truturas e das redes de transporte rápido, que a preocupação em "otimizar o ambiente da empresa" revelou-se mais importante do que a busca do equilíbrio territorial.

As preocupações predominantes para os "aménageurs" dizem respeito, no caso, à otimização dos "efeitos espaciais" das intervenções, quer dizer, os efeitos de polarização-treinamento-indução que a criação ou a implantação de uma atividade de produção ou de um serviço podem gerar no espaço local ou regional (donde a importância dada aos estudos de impacto). As estratégias espaciais dos "aménageurs" são, por definição, orientadas para o longo prazo.

7 O Dicionário de Geografia de John Small e Michael Witherick. (Publicações Dom Quixote, Lda., Lisboa, Portugal, 1986) define este conceito como: "pequena região de França com uma unidade baseada em características da paisagem e que se distinguem das suas áreas vizinhas. Alguns nomes de pays são derivados de unidades administrativas feudais ou de famílias (por ex. Valois), de características marcantes (por ex. Champagne úmido), outros de tipos de uso da terra (por ex. Pays noir) e alguns de um centro urbano próximo (por ex. Lyonnais)".

O Dicionário de língua francesa Petit Robert o define como "a parte do país (nação) de que se fala" que forma uma unidade pelos seus "costumes, tradições" e até às vezes "linguagem local". 
$D$ - Com a passagem do crescimento à crise $e$ com a dupla mudança de sistema de produção e de modelo de desenvolvimento, a atitude dos poderes públicos para com os espaços de intervenção mudou.

Por muitos motivos, os anos 60-70 correspondem à idade de ouro do "aménagement" tecnocrático. Tudo se decide em Paris; a menor solicitação de autorização para construir ou para "aménager" deve "passar por" Paris, onde são definidas as linhas dos grandes esquemas diretores setoriais (por ex. auto-estrada, universidade), mas também os perímetros de todo espaço a ser "aménagé" (ex: comissariados regionais, missões interministeriais, áreas metropolitanas, zonas industriais e portuárias). O espaço de intervenção do "aménagement" na França parece portanto um verdadeiro patchwork de perímetros específicos definidos no topo da decisão administrativa.

Podemos considerar que esta primeira fase acaba com o "discurso de Lyon": o Primeiro Ministro da época declarou naquela cidade que "doravante, os poderes públicos devem favorecer a mobilidade dos homens em direção aos empregos", o que quer dizer que a França deve passar de uma política territorial até então favorável a uma dispersão geográfica dos investimentos e dos empregos (cf: a temática de viver no "pays") a uma política que favoreça a concentração geográfica dos homens nas grandes cidades e nas áreas metropolitanas (onde criam-se empregos). As crises petrolíferas, as dificuldades crescentes do sistema de produção fordista e o fim do crescimento geral deixaram suas marcas.

A década de oitenta marca uma verdadeira ruptura. É a época do reconhecimento da Região como coletividade territorial de pleno exercício, da política de descentralização administrativa, das primeiras verdadeiras transferências de competências para as coletividades territoriais e locais. Então, os espaços institucionais suplantam os perímetros específicos como "territórios normais" do "aménagement", o planejamento contratual se generaliza e permite que as coletividades multipliquem seus projetos, grande parte das ações de "aménagement" passam sob a autoridade direta das Regiões. Como a concorrência especial se acentua, o modelo tradicional do desequilíbrio Capital-Interior tende a se reproduzir dentro dos territórios regionais.

Pode-se considerar que os anos noventa correspondem à "época das tentativas de reajustamentos territoriais". A idéia de reagrupar os meios das coletividades não é nova (os sindicatos intercomunais existem há muito tempo). A novidade está na aprovação da idéia de que a elaboração de um projeto coletivo de desenvolvimento - "aménagement" - requer o reagrupamento dos meios e das capacidades das coletividades envolvidas para que se atinja o "patamar de potenciais" necessário à implementação de um projeto de planejamento a longo prazo. Originaram-se então as diversas tentativas de reajustamento que marcam os anos noventa: as comunidades de Municípios (para as pequenas coletividades) e as comunidades de cidades (sobretudo no quadro regional) em 1992, os "pays" (reagrupamento de 2-3 cantões que apresentam uma certa unidade histórica, cultural, econômica, e que podem servir de quadro para projetos locais de "aménagement") em 1995, a definição das 7 Grandes Obras de "aménagement" (para a concepção e a implantação dos grandes projetos de interesse inter-regional) em 1997, as comunidades de aglomeração (para os grandes conjuntos urbanos) em 1999. Estes reajustamentos são recentes demais para que se possam apreciar os seus resultados; porém podem-se fazer duas observações: só acrescentam novas entidades territoriais, sem questionar as estruturas institucionais tradicionais (mas é possível mexer nas competências dos eleitos?), até o presente, as transferências locais de competências para os benefícios destas novas entidades continuam sendo um problema delicado.

E - Ao longo das últimas décadas, dois fenômenos externos influenciaram a evolução dos territórios do "aménagement" na França: a existência da União Européia, de um lado, e o desenvolvimento da globalização, de outro.

Pela não previsão nos tratados originais da implantação de uma política comum de "aménagement", a influência da C.E.E. permanece por muito tempo limitada a intervenções indiretas severamente controladas pelo Estado: definição de algumas grandes infra-estruturas de transporte de interesse europeu (eixos ferroviários TEE, estradas, canais e rios de grande importância) e sobretudo, auxílios financeiros para os projetos de renovação e de reconversão das regiões em crise (regiões rurais de montanha em vias de despovoamento, antigas regiões industriais). O rigor do controle de Estado decorre do "dogma gaulês" que pesava sobre a França: toda intervenção direta das instâncias comunitárias seria assimilada a uma ingerência nos assuntos interiores da França (o bloqueio que diz respeito ao "aménagement" é, portanto, de natureza política).

As mudanças significativas intervêm a partir do final dos anos setenta, quando se afirmam, de um lado, o poder crescente das regiões, e de outro, os poderes supranacionais da comunidade européia. Ao longo dos anos seguintes, os elementos de uma verdadeira política européia de "aménagement" se organizam: os programas de subvenção às regiões de fronteira e aos pólos europeus, a definição dos primeiros grandes esquemas europeus de "aménagement" (ex: a fachada atlântica), a ajuda à constituição de verdadeiras redes euro- 
péias entre os países membros (ex: redes das cidades européias, das tecnópoles, dos eixos de transporte a grande velocidade). Com a Europa, passou-se então progressivamente de uma intervenção financeira de salvação das economias regionais enfraquecidas a preocupações de "aménagement" que visam a efetuar uma melhor integração espacial dentro da União Européia.

Os efeitos da mundialização (globalização) sobre o "aménagement" do território são mais delicados de se delimitar. Acirrando a competição pelo espaço, a mundialização é sem dúvida alguma responsável por uma boa parte das mudanças ocorridas na escala local (no sentido amplo): a corrida para a atratividade, a impor-tância da oferta às empresas, a necessidade de um reagrupamento dos potenciais das coletividades, o papel crescente de uma boa integração dos espaços locais. Por outra parte, a mundialização acentuou o rigor da separação das funções de gestão entre o sistemamundo e os sistemas locais: para as instituições internacionais e os grandes grupos, a gestão da economia para os organismos e os eleitos locais, a gestão do social. A mundialização, em termos de "aménagement", vem a ser então o meio de "legitimizar" os fenômenos de marginalização (dos homens, das atividades, dos espaços), de desigualdades regionais, de reconcentração nos pontos fortes do território. Mais do que nunca, o "aménagement" do território, como o mostra o exemplo francês, deve conformar-se com o paradigma da rentabilidade.

\section{NOVAS TECNOLOGIAS E DIMENSÃO ESPACIAL}

A - Em que medida a emergência das novas tecnologias da informação e da comunicação (NTIC) modificou o significado e o valor relativo da dimensão espacial no "aménagement" do território? Duas razões, pelo menos, justificam que se formule hoje tal pergunta: estas novas tecnologias transtornaram as condições de acesso à informação, que se tornou por si só um valor altamente estratégico para todas as empresas, os poderes públicos na França (cf. supracitado) apostaram muito sobre as NTIC na sua política de "aménagement", com a idéia implícita de que estas tecnologias permitiriam efetivar por todas as partes a combinação Comunicação-Formação-Pesquisa (cf. a rede TRANSPAC de transferência de dados numéricos, as redes TRANSFIX e NUMERIS de transferência de dados vocais e de imagens, a criação dos Centros Regionais de Inovação e de Transferência Tecnológica).

B - Muitos são os economistas que, baseandose no caráter discreto que as NTIC permitem em matéria de processos de produção, defendem que estas tecnologias facilitam a disjunção funcional e a segmentação técnica do trabalho e, por conseguinte, as divisões sociais e espaciais do trabalho. Estes fenômenos podem ser verificados por toda parte em nível local. Em contrapartida, não se pode dizer o mesmo das conclusões de muitos economistas: a dispersão espacial das atividades pode ser total em razão da "indiferenciação do espaço", a proximidade no espaço geográfico deixa doravante de ser interessante, a única necessidade incontornável hoje é aquela da conexão com as redes.

As realidades do espaço geográfico, e dos territórios do "aménagement", contradizem estes postulados da teoria econômica. $\mathrm{Na}$ escala dos espaços do "aménagement", em geral não existem espaços homogêneos e isotrópicos (aqueles da teoria econômica), e sim espaços geográficos mais ou menos diferenciados, que oferecem recursos e oportunidades mais ou menos variados, constituindo meios mais ou menos atrativos e mais ou menos favoráveis à inovação, à aprendizagem, às parcerias e sinergias entre os atores. Na escala dos espaços do "aménagement", o postulado da "indiferenciação do espaço" não é muito aceitável, enquanto a proximidade geográfica muitas vezes é um fator decisivo na dinâmica dos meios inovadores (se a proximidade não tem mais interesse, por que multiplicar as tecnópoles e outros parques tecnológicos pelo mundo afora?).

Poucos são, na França, os casos de implantação isolada. Na maioria das vezes, trata-se de atividades que utilizam tecnologias banalizadas e que não precisam recorrer às sociedades de serviços sofisticados que acompanham as NTIC.

A posição dos economistas a respeito das grandes possibilidades de dispersão espaciais intro-duzidas pelas NTIC sugere que estas tornaram menos atrativas as economias de aglomeração; pode-se dizer o mesmo dos efeitos sobre as economias de escala? Para ser eficientes e rentáveis, as redes, os equipamentos técnicos e mais ainda os serviços relacionados exigem que sejam reagrupados ao máximo os volumes de dados a ser tratados. Esta exigência só pode ser satisfeita onde se concentra a demanda, portanto em prioridade nas grandes aglomerações. Antes de facilitar a dispersão espacial das atividades, as NTIC são um fator de concentração no espaço geográfico (ex: a localização das sociedades de serviços informáticos). Em compensação, na falta de atividades, a demanda é por demais fraca na maioria das regiões periféricas para justificar tais investimentos, o que aumenta a sua marginalização (neste tipo de região, a criação de redes e de equipamentos técnicos depende de uma política de treinamento antecipativa muito voluntarista, para atrair atividades e provocar o surgimento de uma demanda regional. Mas 
quem pode investir hoje para resultados hipotéticos depois de amanhã? É um problema clássico do "aménagement" do território).

C - Existe entretanto um domínio no qual as NTIC são fonte de grandes mudanças: aquele da organi-zação geográfica do trabalho. Estas novas tecnologias permitem fracionar até o infinito o trabalho, ao mesmo tempo no espaço e no tempo, donde o desenvolvimento do trabalho a distância e em particular o teletrabalho (ex: trabalhos informatizados de secretaria, registro de dados urbanos, guichês de grandes empresas). A prática do teletrabalho permite às empresas aproveitar-se das diferenças de custo do trabalho entre os países ricos e aqueles de baixos salários (por exemplo, a cidade de Lyon manda digitar a sua guia telefônica nas Filipinas), entre regiões penalizadas por sobretaxas devidas a um congestionamento e regiões cuja mão de obra é mais barata (em todas as metrópoles européias multiplica-se o compartilhamento por conjuntos de médicos, advogados, etc. de secretarias informatizadas). Ao facilitar as transferências de empregos e de pequenas e médias empresas, o trabalho a distância deveria permitir, de acordo com os poderes públicos, a revitalização de algumas regiões atrasadas ou em crise. Dada a natureza dos empregos em questão, é muito possível que estas transferências acentuem as clivagens qualitativas no espaço geográfico.

D - Além das NTIC por si só, pode-se dizer que a inovação tecnológica como um todo, pelas suas exigências e pelas suas especificidades, tornou-se um dos grandes responsáveis pela crescente diferenciação entre os territórios das empresas e os territórios institucionais. Nos primeiros, a rede funcional da firma (estrutura formal e fechada) assim como o meio de implantação (estrutura informal e aberta) tornam-se cada vez mais importantes. A diferenciação territorial, que concerne evidentemente as atividades-funções-tecnologias utilizadas-produtos-força de trabalho procurada, está na origem das estratégias espaciais diversificadas implementadas pelas empresas; estratégias que continuam acentuando as clivagens no espaço geográfico, a des- peito dos "esforços corretivos" das políticas de "aménagement".

\section{CONCLUSÃO}

Tema recorrente em todas as literaturas que tratam do "aménagement", o conceito de "escala pertinente" sem dúvida deve ser classificado, assim como as grades de fatores de localização significativas ou ainda a famosa "localização ótima" dos economistas, entre os mitos contestáveis.

Na questão do "aménagement" do território, uma escala espacial só pode ser pertinente em relação a um objeto preciso. Ao inverso dos estudos sobre os fatores de localização, desenvolvidos por muitos geógrafos e economistas, a pertinência de um recorte territorial não se decide nem a priori, nem a posteriori, e sim na hora da implantação do projeto. E é muito evidente que esta pertinência é muito frágil: a menor mudança nas conjunturas político-econômico-tecnológicas pode fazê-la desaparecer.

Em matéria de "aménagement", encontrar a escala pertinente é quase tão impossível quanto a localização ótima dos economistas. A opção por uma localização deve permitir à empresa minimizar seus custos maximizando seus benefícios. Este resultado só pode ser atingido de forma "ótima" em função do estado temporário de uma combinação complexa cujos componentes têm uma mobilidade específica: níveis dos salários, acesso aos recursos, tecnologias, conjunturas política e econômica, ofertas do meio... etc. Otimalidade e pertinência são dois fenômenos sempre fugitivos.

Por fim, para a sua inscrição no espaço, o "aménagement" pode escolher entre um espaço aberto muitas vezes obsoleto (o território institucional), um espaço organizado com outros objetivos (o território das empresas), um espaço adaptado porém de pertinência efêmera (o território específico). A escolha da dimensão espacial não é a menos problemática das escolhas que o "aménagement" do território deve fazer. 